\title{
Self-selection of ethanol as wine by rats
}

\section{ROGER W. BLACK and STEPHEN STRAUB \\ Lniversity of South Carolina. Columbia. S. C. 29208}

Rats were given access to wine [19\% (v/v) ethanol] in their home cages. Food and water were continuously available. Throughout 168 days of observation, the Ss consumed substantial quantities of wine and greater amounts of ethanol than are usually reported. Wine appears to be a suitably palatable solution for animal studies of alcoholism.

The importance of finding an animal model of the human alcoholic has been acknowledged for sometime (e.g., Lester, 1966). An obvious characteristic of such a model would be the chronic, voluntary ingestion of ethanol in quantities sufficient to produce physical dependence. Most laboratory animals under routine maintenance conditions, however, do not ingest such quantities of ethanol but, rather, appear to find ethanol aversive (Myers \& Veale, 1972).

Among the techniques that have been employed in attempts to increase ethanol consumption by laboratory animals is that of enhancing the palatability of the solution containing ethanol (FitzGerald. 1972; Lester, 1966: Myers \& Veale, 1972). Although this procedure has not been reported to produce physical dependence, it does appear in some cases to increase voluntary ingestion of ethanol. Thus, Myers, Stoltman, \& Martin (1972) conclude that "any appropriate behavioral regimen for the development of dependence must include a palatable solution [p. 47]."

The present report describes the relatively long-term consumption of wine by albino rats. The wine employed proved to be a relatively palatable ethanol solution, which led to levels of ethanol consumption substantially higher than those usually obtained with a $19 \%$ ethanol concentration.

\section{METHOD}

The Ss were nine male and seven female Sprague-Dawley albino rats. At 90-100 day's of age. the Ss were placed in individual wire cages in a rack located in a quiet. air-conditioned room that was maintained on a 10-h-dark. 14-h-light cycle. Purina Lab Chow was available ad lib in each cage throughout the investigation. Liquid was continuously available from two $100-\mathrm{ml}$ graduated drinking tubes mounted on the front of each cage. Each tube was equipped with a metal collector for spillage. Throughout the course of the study. one tube contained tap water while the other contained California white port wine (19\% ethanol $v / v)$. The thibes were refilled at $24-h$ intervals. at which time measures of fluid consumption were obtained. corrected for the small amount of spillage that occasionally occurred. and recorded. For the first 42 days. only wine consumption was recorded. but thereafter both wine and water consumption records were kept. The Ss were weighed on the day they were first placed in their individual cages. after 42 days. and at the end of the 168 days of observation. Except for these procedures. the Ss were not disturbed.

\section{RESULTS AND DISCUSSION}

Very few of the Ss showed any initial "aversion" to a $19 \%$ ethanol solution where offered as a sweet wine. Thus, during the first 3 weeks, only three Ss drank less than a daily average of $9 \mathrm{ml}$. By the fifth block of weeks, all Ss were drinking more than $10 \mathrm{ml}$ of wine. Thereafter, there was some decrement in absolute wine consumption, which appeared to be largely attributable to five Ss for which wine consumption steadily declined after this point.

Figure 1 represents most of the data collected during the entire 168-day period. The top panel indicates total liquid consumed by males and females during the period in which these data were collected. Overall, the males consumed $55.1 \mathrm{ml}$ of liquid while the females consumed $48.5 \mathrm{ml}$. The middle panel indicated wine consumption as a proportion of daily liquid intake. Overall, this proportion was .32 for males and .34 for females. The bottom panel represents ethanol consumption relative to estimated body weight. Since the Ss were not weighed regularly during the investigation, the estimates of body weight for each $\mathrm{S}$ were obtained by interpolation between the weights that were obtained on Days 1, 42, and 168. It is clear that females consumed more ethanol per kilogram than males, and the difference in this measure over the entire period was signficant $(t=2.17$, $\mathrm{df}=14, \mathrm{p}<.05)$.

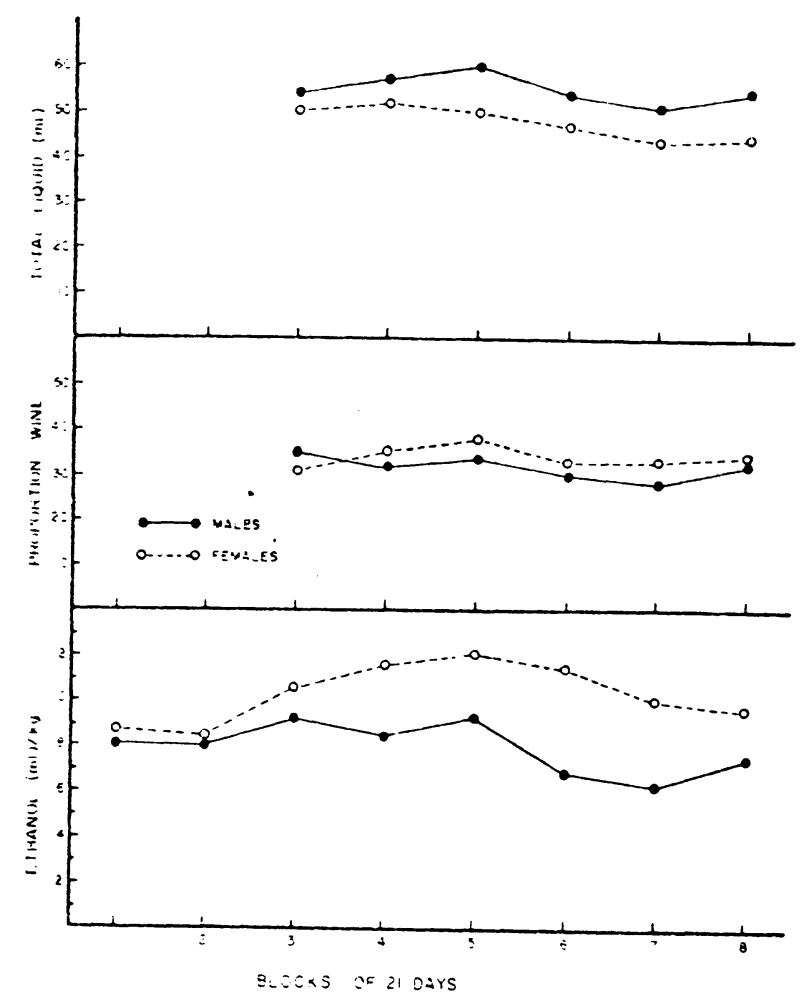

Fig. 1. Total liquid. proportion wine, and milliliters of ethanol per kilogram consumed by males and females during 168 days. 
That wine was not aversive or highly unpalatable to the rats is indicated by the fact that average daily wine consumption for males was $17.9 \mathrm{ml}$ and for females was $16.2 \mathrm{ml}$. Only 2 of the $16 \mathrm{Ss}$ drank an overall average of less than $12 \mathrm{ml}$ per day. Further, wine represented about one-third of the Ss' total fluid intake. Although both food and water were freely available throughout the study. Ss consumed sufficient wine for it to become a significant source of calories, as reflected in their body weights. Thus, a significant relationship was found between Ss' body weight at the end of the 168 days and the proportion of their liquid intake that was wine $(r=$ .83 , df $=14, p<.01$ ). There was, however, no similar relationship between initial body weight and proportion of wine $(\mathrm{r}=.10, \mathrm{df}=14, \mathrm{p}<.20)$ or between final body weight and total liquid consumed $(r=.04$, df $=14$, $\mathrm{p}<.20$ ). Thus. Ss' final body weights reflected their relative preferences for wine during the investigation.

Rats and other laboratory animals find most ethanol solutions aversive when ethanol concentration is much above 5\% (Lester, 1966; Myers \& Veale, 1972). In the present study, ethanol concentration was $19 \%(\mathrm{v} / \mathrm{v})$.
Nevertheless. the Ss did not appear to find the wine aversive. Indeen. they consumed as much or more ethanol in this form as has been reported following rather elaborate procedures (Deutsch \& Koopmans. 1972). It might be expected, then. that if a palatable solution such as wine were employed in experimental situations designed to increase ethanol consumption. laboratory animals might consume quantities sufficient to produce physical dependence.

\section{REFERENCES}

Deutsch, J. A., \& Koopmans, H. S. Preference enhancement for alcohol by passive exposure. Science, 1972, 179, 1242-1243.

Fitz-Gerald, F. L. Voluntray alcohol comsumption on apes. In B. Kissin and $\mathrm{H}$. Begleiter (Eds.), The biology of alcoholism. Vol. 2. New York: Plenum Press, 1972.

Lester, $D$. Self selection of alcohol by animals, human variation and the etiology of alcoholism: A critical review. Quarterly Journal of Studies on Alcohol, 1966, 27, 395-438.

Myers, R. D. Stoltman, W. P., \& Martin, G. E. Effects of ethanol dependence induced artificially in the rhesus monkey on the subsequent preference for ethyl alcohol. Physiology \& Behavior, 1972, 9, 43-48.

Myers, R. D., \& Veale, W. L. The determinants of alcohol preference in animals. In B. Kissin and H. Begleiter (Eds.), The biology of alcoholism. Vol. 2. New York: Plenum Press. 1972.

(Received for publication July 2. 1973.) 